\title{
The relationship between body mass index and poor self-rated health in the South Korean population
}

\author{
Eun-Seok Sung ${ }^{1 \oplus}$, Chang Kyun Choi $\oplus^{2 \odot}$, Ji-An Jeong ${ }^{2}$, Min-Ho Shin ${ }^{2 *}$ \\ 1 Graduate School of Public Health, Chonnam National University, Gwangju, Republic of Korea, \\ 2 Department of Preventive Medicine, Chonnam National University Medical School, Hwasun, Republic of \\ Korea \\ จ These authors contributed equally to this work. \\ *mhshinx@paran.com
}

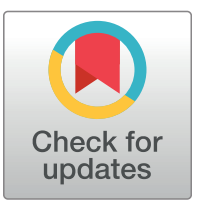

\section{open access}

Citation: Sung E-S, Choi CK, Jeong J-A, Shin M-H (2020) The relationship between body mass index and poor self-rated health in the South Korean population. PLoS ONE 15(8): e0219647. https:// doi.org/10.1371/journal.pone.0219647

Editor: M. Harvey Brenner, University of North Texas Health Science Center, UNITED STATES

Received: June 24, 2019

Accepted: July 15, 2020

Published: August 21, 2020

Copyright: @ 2020 Sung et al. This is an open access article distributed under the terms of the Creative Commons Attribution License, which permits unrestricted use, distribution, and reproduction in any medium, provided the original author and source are credited.

Data Availability Statement: All data are available for free upon registration to the KCHS website (https://chs.cdc.go.kr/).

Funding: The authors received no specific funding for this work.

Competing interests: The authors have declared that no competing interests exist.

\section{Abstract}

\section{Objective}

This study aimed to examine the association between body mass index (BMI) and self-rated health (SRH) in Korean adults.

\section{Methods}

The study included 214,997 adults who participated in the 2016 Korean Community Health Survey. Participants were categorized into four groups according to WHO Asian classification based on their BMI: underweight $\left(<18.5 \mathrm{~kg} / \mathrm{m}^{2}\right)$, normal-weight $(18.5-22.9$ $\left.\mathrm{kg} / \mathrm{m}^{2}\right)$, overweight $\left(23.0-24.9 \mathrm{~kg} / \mathrm{m}^{2}\right)$, obese $\left(25.0-29.9 \mathrm{~kg} / \mathrm{m}^{2}\right)$, and severely obese $\left(\geq 30.0 \mathrm{~kg} / \mathrm{m}^{2}\right)$. Multivariate Poisson regression analysis with sampling weights and robust variance estimators was performed to evaluate the relationship between $\mathrm{BMI}$ categories and poor SRH.

\section{Results}

A J-shaped association was observed between BMI and poor SRH in both sexes. Compared to normal-weight subjects, the age, lifestyle, and comorbidities adjusted prevalence rate ratios (PRRs) in men for poor SRH were 1.73 (95\% confidence interval [CI], 1.60-1.88) for underweight, $0.87(95 \% \mathrm{Cl}, 0.83-0.92)$ for overweight, $0.98(95 \% \mathrm{Cl}, 0.93-1.03)$ for obese, and 1.79 (95\% Cl, 1.63-1.97) for severely obese. In women, compared to normalweight subjects, the age, lifestyle, and comorbidities adjusted PRRs for poor SRH were 1.33 (95\% Cl, 1.26-1.41) for underweight, 1.02 (95\% Cl, 0.98-1.06) for overweight, 1.15 (95\% $\mathrm{Cl}, 1.10-1.19)$ for obese, and $1.42(95 \% \mathrm{Cl}, 1.31-1.53)$ for severely obese. Associations between underweight and $\mathrm{SRH}$ were stronger at older ages than at younger ages, whereas those between high $\mathrm{BMI}$ and $\mathrm{SRH}$ were stronger at younger ages than at older ages. 


\section{Conclusions}

This cross-sectional study using a nationally representative survey observed a J-shaped relationship between $\mathrm{BMI}$ and poor $\mathrm{SRH}$. This association differed depending on age and presence or absence of comorbidities.

\section{Introduction}

Obesity is an important risk factor for the chronic disease burden worldwide [1-3] and is associated with increased morbidity and mortality of various chronic diseases [4]. Recently, underweight has also been associated with high all-cause and cardiovascular mortality [5-8]. However, health-related factors or diseases that mediate this association remains to be elucidated [9]. Self-rated health (SRH) is an indicator of health condition that is a composite of physical, mental, and social well-being [10]. SRH not only reflects the quality of life but also is related to a physical health condition. The association of poor SRH with high morbidity and mortality has been demonstrated not only in the general population as well as in patients with various chronic diseases $[11,12]$. In addition, poor SRH is an important prognostic predictor of diseases such as cancer and heart disease [13-15].

Several studies have explored the association between body mass index (BMI) and SRH [16-21]; however, their results have been inconsistent. Some studies have reported that a higher BMI is associated with poor SRH [19, 20], whereas others have reported a U- or Jshaped association between BMI and poor SRH [16-18, 21, 22]. However, in previous studies, only the association between obesity and poor SRH was assessed, or the association between BMI and poor SRH was not properly assessed due to a lack of underweight subjects. Although there was one study in the Korean population, this one was based on a relatively small study population [23]. Many previous studies have reported sex differences in the association between BMI and poor SRH [17-19, 22]. However, few studies have evaluated the effect modification of sex in Asian populations. Therefore, the present study aimed to investigate the association between BMI and poor SRH in Korean adults and to evaluate whether this association was modified by sex.

\section{Material and methods}

\section{Subjects}

This study used data from the 2016 Korean Community Health Survey (KCHS), which is a detailed survey of a representative sample of the Korean population aged $\geq 19$ years conducted annually since 2008 to provide health statistics at the municipality level [24]. The target population for the KCHS is adults aged $\geq 19$ years living within the jurisdiction of a community health center. The stratum was divided into two stages according to the administrative unit (Dong, Eup, and Myeon) and housing unit (apartments and houses); the smallest administrative district unit (Tong, Ban, and Lee) was selected as the primary sampling unit of the stratum through probability proportionate sampling [24]. Information was collected through face-toface interviews conducted by a trained interviewer. The $2016 \mathrm{KCHS}$ included 228,452 subjects. BMI was missing for 10,371 participants (4.5\%), SRH for 27 participants $(<0.1 \%)$, smoking status for 6 participants $(<0.1 \%)$, alcohol consumption for 70 participants $(<0.1 \%)$, physical activity for 373 participants $(0.2 \%)$, marital status for 208 participants $(0.1 \%)$, household income for 2,376 participants (1.0\%), education level for 342 participants $(0.1 \%)$, the history of 
hypertension for 32 participants ( $<0.1 \%)$, the history of diabetes for 36 participants $(<0.1 \%)$, the history of stroke for 33 participants $(<0.1 \%)$, the history of coronary heart disease for 126 participants $(0.1 \%)$, and the history of arthritis for 76 participants $(<0.1 \%)$. The final analysis included 214,997 participants (94.1\%) without missing values. This study was approved by the Institutional Review Board of the Korea Centers for Disease Control and Prevention (KCDC).

\section{Body mass index}

BMI was based on self-reported height and weight and calculated as weight in kilograms divided by height in meters squared. Correlation coefficients between the measured and selfreported BMI in the subgroup of this survey were high $(r=0.92)$ [25]. Participants were categorized into four groups according to WHO Asian classification [26] based on their BMI as underweight $\left(<18.5 \mathrm{~kg} / \mathrm{m}^{2}\right)$, normal-weight $\left(18.5-22.9 \mathrm{~kg} / \mathrm{m}^{2}\right)$, overweight $\left(23.0-24.9 \mathrm{~kg} / \mathrm{m}^{2}\right)$, obese $\left(25.0-29.9 \mathrm{~kg} / \mathrm{m}^{2}\right)$, and severely obese $\left(\geq 30.0 \mathrm{~kg} / \mathrm{m}^{2}\right)$.

\section{Self-rated health}

SRH was assessed based on responses to the question, "How do you rate your general health status?," rated on a five-point scale widely used [27]. SRH was dichotomized as poor (reported as "poor" or "very poor") or good (reported as "very good," "good," or "moderate").

\section{Covariates}

Lifestyle, socioeconomic status, and comorbidities were investigated in an interview conducted by the trained interviewee. Smoking history was coded as non-, former, or current smokers. The amount and frequency of alcohol consumption were investigated, with alcohol intake was categorized as drinker or non-drinker. Socioeconomic variables considered in this study included marital status (single, married, or divorced/bereaved/separated), educational attainment (uneducated, elementary school, middle school, high school, or college or higher), rural residency, and monthly household income ( $\leq 1.00$ million, 1.01-2.00 million, 2.01-3.00 million, 3.01-4.00 million, or $\geq 4.01$ million South Korean won). Physical activity was coded as whether subjects engaged in moderate or vigorous physical activity, regardless of whether it was performed for leisure or occupation. Moderate physical activity was defined as moderately intense physical activity (e.g., swimming at a slow pace, table tennis, badminton, tennis doubles, etc.) for more than 5 days per week for $30 \mathrm{~min}$ or more. Vigorous physical activity was defined as intense physical activity (e.g., swimming at a fast pace, climbing, cycling, squash, tennis singles, etc.) for more than 3 days per week for $20 \mathrm{~min}$ or more. Comorbidities (if respondents had doctor-diagnosed hypertension, diabetes, stroke, coronary heart disease, or arthritis) were also considered.

\section{Statistical analysis}

Since there was a significant difference in the association between BMI and poor SRH between men and women, all analyses were performed separately for each sex. The relationship between BMI and SRH was assessed using multivariate Poisson regression analysis with robust variance estimators and sampling weights derived from KCHS. Because the prevalence odds ratio tends to overestimate the strength of associations [28], the association between BMI and poor SRH was assessed using the prevalence rate ratio (PRR). The normal-weight group was used as a reference. In the first model, age was adjusted. In the second model, socioeconomic status variables (household income, marital status, education level, and residence type) were added. In the third model, lifestyle variables (smoking, alcohol consumption, and physical activity) were added. In the fourth model, comorbidities (hypertension, diabetes mellitus, 


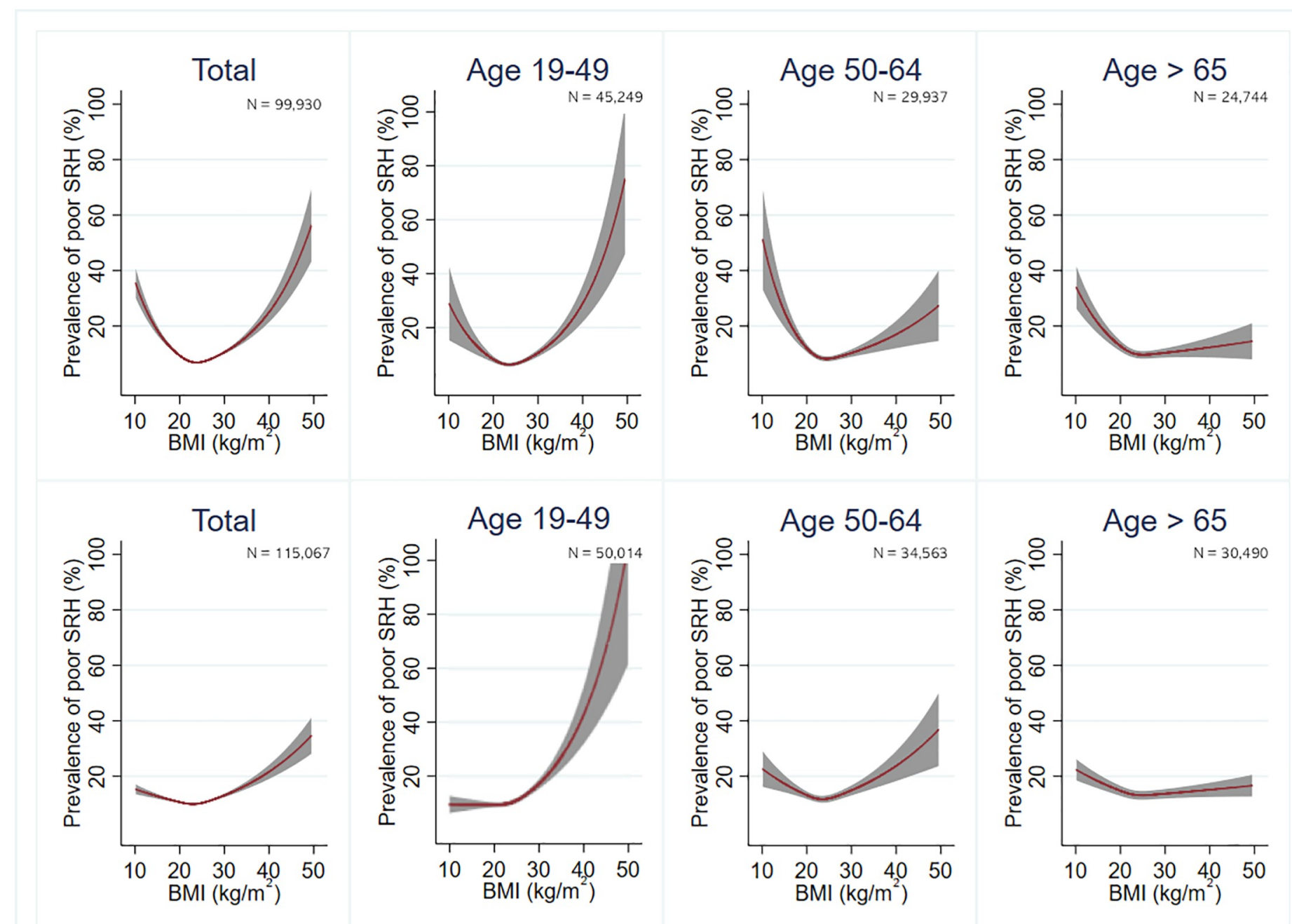

Fig 1. Prevalence of poor self-rated health estimated using a multivariate Poisson regression model with a restricted cubic spline according to age in men (upper row) and women (lower row). Lifestyle, socioeconomic status, and comorbidities were adjusted. The gray band represents the $95 \%$ confidence interval.

stroke, coronary heart disease, and arthritis) were added. Model 4 results were considered the main results. Subgroup analyses were performed according to age and comorbidities.

Restricted cubic splines were used to model the nonlinear relationship between BMI and poor SRH in Figs 1 and 2 using knots at the 5th, 50th, and 95th BMI percentiles based on Harrell's recommended percentiles [29]. Stata version 14.0 (Stata Corp, College Station, TX, USA) was used for the statistical analyses. Statistical significance was defined as $P<0.05$.

\section{Results}

The study population included 99,930 men and 115,067 women. Their baseline characteristics according to BMI categories are presented in Tables 1 and 2. The prevalence of underweight participants was $2.7 \%$ in men and $7.0 \%$ in women, whereas that of obesity was $3.6 \%$ and $2.5 \%$, respectively. In men, compared to normal-weight participants, participants with underweight were older, lived alone, had lower income and education levels, lived in a rural area, engaged in less physical activity, and had lower alcohol consumption. In addition, they had a lower 

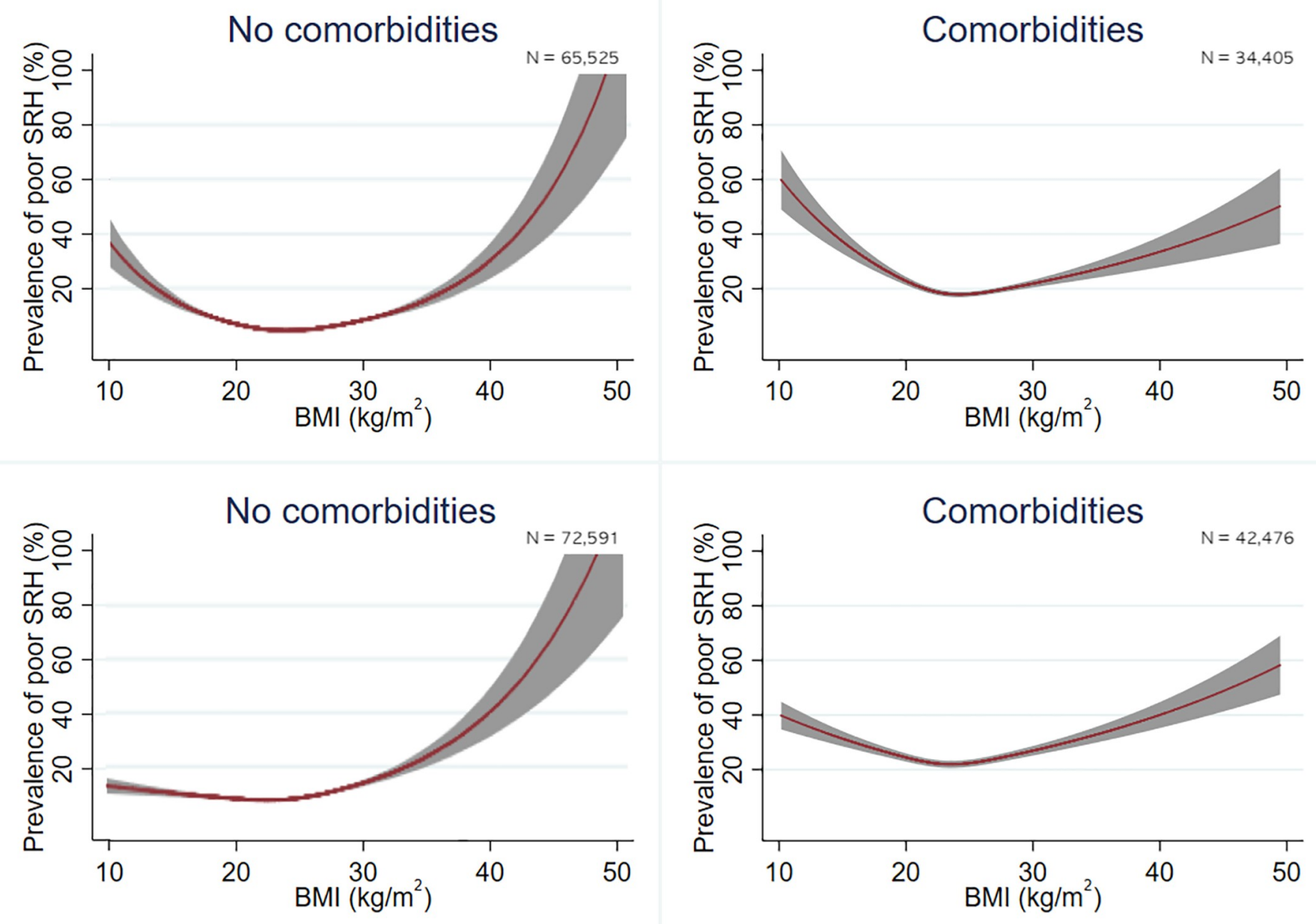

Fig 2. Prevalence of poor self-rated health estimated using a multivariate Poisson regression model with a restricted cubic spline according to the presence of comorbidities in men (upper row) and women (lower row). Lifestyle and socioeconomic status were adjusted. The gray band represents the $95 \%$ confidence interval.

prevalence of hypertension but higher rates of stroke, coronary heart disease, and arthritis. However, these tendencies were reversed in participants with obesity. Compared to normalweight men participants, participants with obesity were younger, were married, had higher income and education levels, lived in a rural area, engaged in more physical activity, and had higher alcohol consumption. In addition, they had a higher prevalence of hypertension and diabetes but lower rates of stroke, coronary heart disease, and arthritis.

Among female participants, compared to normal-weight participants, those with underweight were younger, more likely to be married, had lower income and education levels, lived in rural areas, were engaged in less physical activity, and had lower alcohol consumption. In addition, they had a lower prevalence of hypertension, diabetes, and arthritis. Compared to normal-weight participants, those with obesity were older, had higher income and education levels, lived in cities, and had lower alcohol consumption. In addition, they had a higher prevalence of hypertension, diabetes, stroke, coronary heart diseases, and arthritis.

Table 3 presents the PRRs for poor SRH according to BMI categories. A nonlinear relationship was observed between BMI and poor SRH. Compared to normal-weight subjects, the age- 
Table 1. Baseline characteristics according to the body mass index $\left(\mathrm{kg} / \mathrm{m}^{2}\right)$ categories in men.

\begin{tabular}{|c|c|c|c|c|c|}
\hline Characteristics & Underweight $(<18.5)$ & Normal-weight (18.5-22.9) & Overweight (23.0-24.9) & Obese (25-29.9) & Severely obese $(\geq 30)$ \\
\hline $\mathrm{N}$ & $2,659(2.7)$ & $36,115(36.1)$ & $27,958(28.0)$ & $29,629(29.6)$ & $3,569(3.6)$ \\
\hline Age (years) & $59.8 \pm 21.9$ & $52.6 \pm 18.0$ & $52.6 \pm 15.9$ & $49.7 \pm 15.0$ & $41.5 \pm 14.7$ \\
\hline \multicolumn{6}{|l|}{ Marriage } \\
\hline Single & $636(23.9)$ & $8,114(22.5)$ & $4,501(16.1)$ & $5029(17.0)$ & $1,258(35.2)$ \\
\hline Married & $1,685(63.4)$ & $24,898(68.9)$ & $21,295(76.2)$ & $22,617(76.3)$ & $2,130(59.7)$ \\
\hline Divorce/bereavement/separation & $338(12.7)$ & $3,103(8.6)$ & $2,162(7.7)$ & $1,983(6.7)$ & $181(5.1)$ \\
\hline \multicolumn{6}{|l|}{ Household income (million won) } \\
\hline$\leq 1.00$ & $1,049(39.5)$ & $7,082(19.6)$ & $4,199(15.0)$ & $3,451(11.6)$ & $356(10.0)$ \\
\hline $1.01-2.00$ & $534(20.1)$ & $6,462(17.9)$ & $4,609(16.5)$ & $4,362(14.7)$ & 495 (13.9) \\
\hline $2.01-3.00$ & $401(15.1)$ & $6,913(19.1)$ & $5,453(19.5)$ & $6,002(20.3)$ & $805(22.6)$ \\
\hline $3.01-4.00$ & $294(11.1)$ & $5,902(16.3)$ & $4,925(17.6)$ & $5,584(18.8)$ & $723(20.3)$ \\
\hline$\geq 4.01$ & $381(14.3)$ & $9,756(27.0)$ & $8,772(31.4)$ & $10,230(34.5)$ & $1,190(33.3)$ \\
\hline \multicolumn{6}{|l|}{ Education } \\
\hline Uneducated & $192(7.2)$ & $875(2.4)$ & $413(1.5)$ & $317(1.1)$ & $24(0.7)$ \\
\hline Elementary & $719(27.0)$ & $5,360(14.8)$ & $3,505(12.5)$ & $2,783(9.4)$ & $221(6.2)$ \\
\hline Middle school & $392(14.7)$ & $4,427(12.3)$ & $3,392(12.1)$ & $3,060(10.3)$ & $234(6.6)$ \\
\hline High school & $699(26.3)$ & $11,153(30.9)$ & $8,823(31.6)$ & $9,676(32.7)$ & $1,073(30.1)$ \\
\hline More than college & $657(24.7)$ & $14,300(39.6)$ & $11,825(42.3)$ & $13,793(46.6)$ & 2,017 (56.5) \\
\hline Rural residence & $1,449(54.5)$ & $16,098(44.6)$ & $11,802(42.2)$ & $12,169(41.1)$ & $1,417(39.7)$ \\
\hline Physical activity & $457(17.2)$ & $9,624(26.6)$ & $7,861(28.1)$ & $8,200(27.7)$ & $1,017(28.5)$ \\
\hline \multicolumn{6}{|l|}{ Smoking } \\
\hline Nonsmoker & $656(24.7)$ & $9,095(25.2)$ & $6,977(25.0)$ & $7,150(24.1)$ & $1,039(29.1)$ \\
\hline Former smoker & $966(36.3)$ & $12,640(35.0)$ & $11,209(40.1)$ & $11,811(39.9)$ & $1,049(29.4)$ \\
\hline Current smoker & $1,037(39.0)$ & $14,380(39.8)$ & $9,772(35.0)$ & $10,668(36.0)$ & $1,481(41.5)$ \\
\hline Alcohol intake & $1,226(46.1)$ & $22,519(62.4)$ & $18,520(66.2)$ & $20,333(68.6)$ & $2,424(67.9)$ \\
\hline Hypertension & $498(18.7)$ & $7,139(19.8)$ & $7,407(26.5)$ & $9,124(30.8)$ & $1,210(33.9)$ \\
\hline Diabetes & $254(9.6)$ & $3,465(9.6)$ & $3,371(12.1)$ & $3,700(12.5)$ & $484(13.6)$ \\
\hline Stroke & $101(3.8)$ & $955(2.6)$ & $699(2.5)$ & $638(2.2)$ & $56(1.6)$ \\
\hline Coronary heart disease & $131(4.9)$ & $1,231(3.4)$ & $1,066(3.8)$ & $1,137(3.8)$ & $113(3.2)$ \\
\hline Arthritis & $237(8.9)$ & $2,100(5.8)$ & $1,680(6.0)$ & $1,653(5.6)$ & $159(4.5)$ \\
\hline
\end{tabular}

All values are given as $\mathrm{n}(\%)$ or mean \pm standard deviation.

https://doi.org/10.1371/journal.pone.0219647.t001

adjusted PRRs for poor SRH across BMI levels $\left(<18.5,23.0-24.9,25.0-29.9\right.$, and $\left.\geq 30 \mathrm{~kg} / \mathrm{m}^{2}\right)$ were 1.86 (95\% CI, 1.72-2.01), 0.87 (95\% CI, 0.83-0.92), 1.02 (95\% CI, 0.97-1.08), and 2.33 (95\% CI, 2.11-2.56), respectively, for men. Compared to normal-weight subjects, the ageadjusted PRRs for poor SRH across BMI levels $\left(<18.5,23.0-24.9,25.0-29.9\right.$, and $\left.\geq 30 \mathrm{~kg} / \mathrm{m}^{2}\right)$ were 1.37 (95\% CI, 1.29-1.46), 1.09 (95\% CI, 1.05-1.13), 1.38 (95\% CI, 1.33-1.43), and 2.10 (95\% CI, 1.94-2.27), respectively, for women. After further adjustment for demographic, socioeconomic, and lifestyle characteristics in model 3, this U-shaped association was slightly attenuated but remained statistically significant in both sexes. In model 4 with further adjustment for comorbidities, the PRRs of obese and severe obese were attenuated, whereas those for underweight were strengthened. Compared to normal-weight subjects, the PRRs for underweight, overweight, obsess, and severely obese were 1.73 (95\% CI, 1.60-1.88), 0.87 (95\% CI, $0.83-0.92), 0.98$ (95\% CI, 0.93-1.03), and 1.79 (95\% CI, 1.63-1.97), respectively, in men, and in women, the PRR for underweight was 1.33 (95\% CI, 1.26-1.41), the PRR for overweight was 1.02 (95\% CI, 0.98-1.06), the PRR for obese was 1.15 (95\% CI, 1.10-1.19), and the PRR for 
Table 2. Baseline characteristics according to the body mass index $\left(\mathrm{kg} / \mathrm{m}^{2}\right)$ categories in women.

\begin{tabular}{|c|c|c|c|c|c|}
\hline Characteristics & Underweight $(<\mathbf{1 8 . 5})$ & Normal-weight (18.5-22.9) & Overweight (23.0-24.9) & Obese (25-29.9) & Severe obese $(\geq 30)$ \\
\hline $\mathrm{N}$ & $7,997(6.9)$ & $56,964(49.5)$ & $24,965(21.7)$ & $22,225(19.3)$ & $2,916(2.5)$ \\
\hline Age (years) & $47.6 \pm 21.8)$ & $50.2 \pm 17.7)$ & $55.5 \pm 15.1)$ & $56.2 \pm 14.8)$ & $52.3 \pm 16.5)$ \\
\hline \multicolumn{6}{|l|}{ Marriage } \\
\hline Single & $2,403(30.0)$ & $9,247(16.2)$ & $1,741(7.0)$ & $1,430(6.4)$ & $392(13.4)$ \\
\hline Married & $3,818(47.7)$ & $36,548(64.2)$ & $17,573(70.4)$ & $15,403(69.3)$ & $1,842(63.2)$ \\
\hline Divorce/bereavement/separation & $1,776(22.2)$ & $11,169(19.6)$ & $5,651(22.6)$ & $5,392(24.3)$ & $682(23.4)$ \\
\hline \multicolumn{6}{|l|}{ Household income (million won) } \\
\hline$\leq 1.00$ & $1,863(23.3)$ & $10,505(18.4)$ & $5,560(22.3)$ & $5,311(23.9)$ & $715(24.5)$ \\
\hline $1.01-2.00$ & $1,034(12.9)$ & $8,585(15.1)$ & $4,526(18.1)$ & $4,314(19.4)$ & $561(19.2)$ \\
\hline $2.01-3.00$ & $1,257(15.7)$ & $9,853(17.3)$ & $4,471(17.9)$ & $4,153(18.7)$ & $579(19.9)$ \\
\hline $3.01-4.00$ & $1,194(14.9)$ & $9,341(16.4)$ & $3,991(16.0)$ & $3,355(15.1)$ & $465(15.9)$ \\
\hline$\geq 4.01$ & $2,649(33.1)$ & $18,680(32.8)$ & $6,417(25.7)$ & $5,092(22.9)$ & $596(20.4)$ \\
\hline \multicolumn{6}{|l|}{ Education } \\
\hline Uneducated & $1,025(12.8)$ & $4,391(7.7)$ & $1,881(7.5)$ & $1,718(7.7)$ & $223(7.6)$ \\
\hline Elementary & $1,194(14.9)$ & $9,079(15.9)$ & $5,966(23.9)$ & $6,190(27.9)$ & $730(25.0)$ \\
\hline Middle school & $367(4.6)$ & $5,073(8.9)$ & $3,594(14.4)$ & $3,596(16.2)$ & $414(14.2)$ \\
\hline High school & $1,497(18.7)$ & $15,479(27.2)$ & $7,378(29.6)$ & $6,262(28.2)$ & $904(31.0)$ \\
\hline More than college & $3,914(48.9)$ & $22,942(40.3)$ & $6,146(24.6)$ & $4,459(20.1)$ & $645(22.1)$ \\
\hline Rural residence & $3,131(39.2)$ & $22,113(38.8)$ & $10,966(43.9)$ & $10,246(46.1)$ & $1,280(43.9)$ \\
\hline Physical activity & $1,159(14.5)$ & $10,973(19.3)$ & $5,044(20.2)$ & $4,309(19.4)$ & $490(16.8)$ \\
\hline \multicolumn{6}{|l|}{ Smoking } \\
\hline Nonsmoker & $7,331(91.7)$ & $53,846(94.5)$ & $23,839(95.5)$ & $20,962(94.3)$ & $2,638(90.5)$ \\
\hline Former smoker & $258(3.2)$ & $1,364(2.4)$ & $567(2.3)$ & $632(2.8)$ & $135(4.6)$ \\
\hline Current smoker & $408(5.1)$ & $1,754(3.1)$ & $559(2.2)$ & $631(2.8)$ & $143(4.9)$ \\
\hline Alcohol intake & $2,534(31.7)$ & $18,454(32.4)$ & $6,848(27.4)$ & $5,670(25.5)$ & $788(27.0)$ \\
\hline Hypertension & $1,169(14.6)$ & $10,189(17.9)$ & $7,217(28.9)$ & $8,611(38.7)$ & $1,338(45.9)$ \\
\hline Diabetes & $394(4.9)$ & $3,737(6.6)$ & $2,650(10.6)$ & $3,211(14.4)$ & $594(20.4)$ \\
\hline Stroke & $125(1.6)$ & $814(1.4)$ & $437(1.8)$ & $543(2.4)$ & $81(2.8)$ \\
\hline Coronary heart disease & $179(2.2)$ & $1,194(2.1)$ & $748(3.0)$ & $898(4.0)$ & $142(4.9)$ \\
\hline Arthritis & $1,081(13.5)$ & $7,960(14.0)$ & $5,218(20.9)$ & $5,909(26.6)$ & $830(28.5)$ \\
\hline
\end{tabular}

All values are given as $\mathrm{n}(\%)$ or mean \pm standard deviation.

https://doi.org/10.1371/journal.pone.0219647.t002

severely obese was 1.42 (95\% CI, 1.31-1.53). The interaction by sex was significant ( $P$ for interaction $<0.001$ ).

Table 4 presents the PRRs for poor SRH according to the BMI categories, stratified by age and comorbidities. In both sexes, the magnitude of the association between obesity and poor SRH decreased with increasing age. The magnitude of the association between underweight and poor SRH was smaller in the age group 65 years or older than in the young age groups. In addition, a U-shaped association between BMI and poor SRH was prominent in subjects without comorbidities compared to subjects with comorbidities.

Figs 1 and 2 show the adjusted prevalence of poor SRH from restricted cubic spline models in both sexes. In both sexes, there was a J-shaped association between BMI and poor SRH, with the lowest risk observed for a BMI of $23-24.9 \mathrm{~kg} / \mathrm{m}^{2}$ in both men and women. This association was more prominent in men than in women. When participants are older or accompanied by comorbidities, the association between BMI and SRH is less pronounced than those who are not. 
Table 3. Associations between the body mass index $\left(\mathrm{kg} / \mathrm{m}^{2}\right)$ categories and self-rated health.

\begin{tabular}{|c|c|c|c|c|c|}
\hline & BMI categories & Model 1 & Model 2 & Model 3 & Model 4 \\
\hline \multirow[t]{5}{*}{ Men } & Underweight $(<18.5)$ & $1.86(1.72-2.01)$ & $1.65(1.53-1.79)$ & $1.57(1.46-1.70)$ & $1.73(1.60-1.88)$ \\
\hline & Normal-weight (18.5-22.9) & 1.00 (Reference) & 1.00 (Reference) & 1.00 (Reference) & 1.00 (Reference) \\
\hline & Overweight (23.0-24.9) & $0.87(0.83-0.92)$ & $0.92(0.88-0.97)$ & $0.94(0.89-0.99)$ & $0.87(0.83-0.92)$ \\
\hline & Obese (25.0-29.9) & $1.02(0.97-1.08)$ & $1.11(1.05-1.17)$ & $1.13(1.07-1.19)$ & $0.98(0.93-1.03)$ \\
\hline & Severe obese $(\geq 30)$ & $2.33(2.11-2.56)$ & $2.29(2.08-2.52)$ & $2.29(2.07-2.52)$ & $1.79(1.63-1.97)$ \\
\hline \multirow[t]{5}{*}{ Women } & Underweight $(<18.5)$ & $1.37(1.29-1.46)$ & $1.30(1.23-1.38)$ & $1.27(1.20-1.35)$ & $1.33(1.26-1.41)$ \\
\hline & Normal-weight (18.5-22.9) & 1.00 (Reference) & 1.00 (Reference) & 1.00 (Reference) & 1.00 (Reference) \\
\hline & Overweight (23.0-24.9) & $1.09(1.05-1.13)$ & $1.06(1.02-1.11)$ & $1.07(1.03-1.11)$ & $1.02(0.98-1.06)$ \\
\hline & Obese (25.0-29.9) & $1.38(1.33-1.43)$ & $1.30(1.25-1.35)$ & $1.29(1.25-1.34)$ & $1.15(1.10-1.19)$ \\
\hline & Severe obese $(\geq 30)$ & $2.10(1.94-2.27)$ & $1.85(1.72-2.00)$ & $1.82(1.68-1.96)$ & $1.42(1.31-1.53)$ \\
\hline
\end{tabular}

Data are presented given as 'prevalence rate ratio (95\% confidence interval)'.

Model 1 was adjusted for age.

Model 2 was additionally adjusted for socioeconomic status (household income, marital status, education level and residential area).

Model 3 was additionally adjusted for lifestyles (smoking, drinking and exercise).

Model 4 was additionally adjusted for comorbidities (hypertension, diabetes mellitus, stroke, coronary heart disease, and arthritis).

https://doi.org/10.1371/journal.pone.0219647.t003

\section{Discussion}

This cross-sectional study using a nationwide sample demonstrated a J-shaped association between BMI and poor SRH in Korean adults. The association between BMI and poor SRH were different according to age and comorbidities.

We found that both underweight and obese were associated with poor SRH. Except for those that did not evaluate the relationship with underweight $[19,20]$, previous studies have reported U- or J-shaped relationships but have reported inconsistent results regarding sex-

Table 4. Stratified analysis of the association between the body mass index $\left(\mathrm{kg} / \mathrm{m}^{2}\right)$ categories and self-rated health.

\begin{tabular}{|c|c|c|c|c|c|c|c|}
\hline & & Underweight $(<18.5)$ & Normal (18.5-22.9) & Overweight (23.0-24.9) & Obese (25.0-29.9) & Severely obese $(\geq 30)$ & $\mathbf{P}$ for interaction \\
\hline \multirow[t]{7}{*}{ Men } & Age*, years & & & & & & \\
\hline & 19-49 & $1.97(1.52-2.57)$ & 1 (reference) & $0.85(0.75-0.98)$ & $1.22(1.08-1.36)$ & $2.23(1.92-2.60)$ & \multirow[t]{3}{*}{$<0.001$} \\
\hline & $50-64$ & $2.22(1.85-2.67)$ & 1 (reference) & $0.89(0.82-0.98)$ & $0.93(0.85-1.01)$ & $1.20(1.00-1.45)$ & \\
\hline & $\geq 65$ & $1.49(1.38-1.62)$ & 1 (reference) & $0.86(0.81-0.92)$ & $0.84(0.79-0.90)$ & $1.00(0.82-1.21)$ & \\
\hline & Comorbidity** & & & & & & \\
\hline & No & $2.08(1.84-2.35)$ & 1 (reference) & $0.85(0.77-0.94)$ & $1.08(0.98-1.19)$ & $2.53(2.15-2.96)$ & \multirow[t]{2}{*}{$<0.001$} \\
\hline & Yes & $1.40(1.28-1.53)$ & 1 (reference) & $0.87(0.82-0.93)$ & $0.90(0.85-0.95)$ & $1.29(1.15-1.45)$ & \\
\hline \multirow[t]{7}{*}{ Women } & Age* years & & & & & & \\
\hline & 19-49 & $1.45(1.27-1.67)$ & 1 (reference) & $1.33(1.19-1.49)$ & $1.68(1.51-1.87)$ & $2.63(2.20-3.13)$ & \multirow[t]{3}{*}{$<0.001$} \\
\hline & $50-64$ & $1.62(1.40-1.87)$ & 1 (reference) & $0.96(0.89-1.03)$ & $1.12(1.04-1.21)$ & $1.29(1.13-1.48)$ & \\
\hline & $\geq 65$ & $1.20(1.13-1.27)$ & 1 (reference) & $0.93(0.89-0.97)$ & $0.95(0.91-0.99)$ & $0.94(0.86-1.03)$ & \\
\hline & Comorbidity** & & & & & & \\
\hline & No & $1.50(1.35-1.66)$ & 1 (reference) & $1.12(1.03-1.21)$ & $1.44(1.32-1.57)$ & $2.52(2.10-3.02)$ & \multirow[t]{2}{*}{$<0.001$} \\
\hline & Yes & $1.21(1.14-1.28)$ & 1 (reference) & $0.93(0.89-0.97)$ & $1.01(0.97-1.05)$ & $1.23(1.15-1.33)$ & \\
\hline
\end{tabular}

Data are presented as 'prevalence rate ratio ( $95 \%$ confidence interval)'.

*adjusted for age, household income, marital status, education level, residence type, smoking, drinking, physical activity, hypertension, diabetes mellitus, stroke, coronary heart disease, and arthritis.

**adjusted for age, household income, marital status, education level, residence type, smoking, drinking and physical activity. 
specific relationships [17, 18, 21, 22]. Heo et al. reported a J-shaped relationship between BMI and health-related quality of life [21]. Similar to the present study, when adjusted for comorbidities, the association between underweight and poor SRH was strengthened, while that between overweight and obesity with poor SRH was attenuated. In the Canadian Community Health Survey [17], BMI showed a U-shaped association with poor SRH in both sexes. In a study based on the National Health Interview Survey from 1997 to 2005 [18] and a study based on the World Health Survey (2002-2004) [22], the association between underweight and poor SRH was more evident in men whereas that between obesity and poor SRH was more evident in women. However, the Sault Antenatal Care Programme in Sweden [16] observed a Ushaped relationship in women but a linear relationship in men. This study was conducted in expectant parents, rather than in the general population, and was a small study with fewer than 1,000 subjects, which may have resulted in the discordance from the results of previous studies. Only one previous study was based on Korean. Noh et al. assessed the relationship between BMI categorized as WHO Asian classification and SRH scores, and SRH scores were the highest in the normal-weight $\left(18.5-22.9 \mathrm{~kg} / \mathrm{m}^{2}\right)$ [23]. Compared to normal-weight, the odds ratio (OR) of poor SRH score was 1.60 in underweight, 1.08 in overweight, 1.72 in obese, and 3.97 in severely obese.

The underlying mechanism for the relationship between underweight and poor SRH can be explained as follows: first, underweight is associated with sarcopenia [30]. Subjects with sarcopenia or decreased muscle mass have lower exercise capacity and lower levels of physical activity, both of which are associated with poor SRH; second, the relationship between underweight and poor SRH could be explained by lifestyle factors and pre-existing comorbidities [31]. Although we adjusted for lifestyle factors and several comorbidities, unmeasured confounding and residual confounding is still possible to explain the association. The relationship between obesity and poor SRH may be mediated by obesity-related comorbidities. Numerous studies have reported causal relationships between obesity and cardiovascular diseases and cancer [32-34], which can lead to poor SRH and poor quality of life [35]. In our study, after adjusting for comorbidities, the strength of the relationship decreased by more than $30 \%$. Additionally, obesity is associated with reduced physical activity and lower exercise capacity, and both conditions are associated with poor SRH.

The sex difference in the association between BMI and SRH may be partly due to differences in body fat distribution. At the same BMI, women tend to have higher body fat than men across all ages [36, 37]. In contrast, visceral adipose tissue increases more in men as BMI increases in those age $<40$ years, whereas the association between visceral adipose tissue and BMI does not differ according to sex in those aged $\geq 40$ years [37]. Unfortunately, as this study did not measure total body fat or lean body mass, whether the relationship between BMI and SRH varied depending on differences in fat distribution could not be assessed.

In the present study, the association between BMI and poor SRH varied with age. The associations between underweight and poor SRH strengthened with age, whereas those between the high BMI and poor SRH attenuated with age. Hulman et al. reported that the BMI trajectory of those who reported poor SRH had declined more than that of those not reporting poor SRH in subjects aged over 80 years [38]. Similar to this study, a large population-based cohort study of 3.6 million adults in the UK reported that the associations between BMI and mortality varied by age and those between high BMI and mortality attenuated with age [31].

In this study, the relationship between underweight and poor SRH was more apparent in subjects with comorbidity. These results indicate the possibility of reverse causality due to comorbidity. Our findings are consistent with previous studies. In the Scottish Health Survey, there was an inverted U-shaped association between BMI and health-related quality of life, and participants with metabolic comorbidities had poor quality of life compared to those 
without metabolic comorbidities across all BMI categories [39]. In prospective studies of mortality, the association between BMI and mortality was also U-shaped, and the strength of the association between underweight and mortality was greater in healthy never-smoker compared to never-smoker $[40,41]$.

The strength of this study is the large, nationally representative sample size. Also, since this study had a relatively high percentage (5\%) of underweight, when compared to previous studies $(<2.5 \%)[17,18,21]$, we could clarify the relationship between underweight and SRH. However, this study has some limitations. First, the cross-sectional design leads to difficulty in assessing causal relationships. Second, poor SRH could be underreported in face-to-face interviews, which could induce differential misclassification of poor SRH in participants with high or low BMI. Third, some comorbidities that could affect both self-rated health and underweight were not considered. Health conditions, such as chronic obstructive pulmonary diseases (COPD) and sarcopenia, are associated with underweight and these are also associated with quality of life.

\section{Conclusion}

Both obesity and underweight were associated with an increased propensity for poor SRH, even after adjusting for demographic, socioeconomic, lifestyle variables and comorbidities. A J-shaped was observed between BMI and poor SRH in a nationwide sample of Korean adults. In addition, age and comorbidities modified the association between BMI and poor SRH. These results suggest that both underweight and overweight are risk factors for poor SRH. However, prospective studies using fat distribution are needed to clarify the causal relationship between these two variables.

\section{Acknowledgments}

This manuscript is a revision of the first author (ESS)'s $\mathrm{PhD}$ thesis from Chonnam National University.

\section{Author Contributions}

Conceptualization: Min-Ho Shin.

Formal analysis: Eun-Seok Sung, Chang Kyun Choi, Min-Ho Shin.

Supervision: Min-Ho Shin.

Writing - original draft: Eun-Seok Sung, Chang Kyun Choi, Ji-An Jeong, Min-Ho Shin.

Writing - review \& editing: Eun-Seok Sung, Chang Kyun Choi, Ji-An Jeong, Min-Ho Shin.

\section{References}

1. Quesenberry CP Jr, Caan B, Jacobson A. Obesity, health services use, and health care costs among members of a health maintenance organization. Archives of internal medicine. 1998; 158(5):466-72. https://doi.org/10.1001/archinte.158.5.466 PMID: 9508224.

2. Visscher TL, Seidell JC. The public health impact of obesity. Annual review of public health. 2001; 22:355-75. https://doi.org/10.1146/annurev.publhealth.22.1.355 PMID: 11274526.

3. Flynn MA, McNeil DA, Maloff B, Mutasingwa D, Wu M, Ford C, et al. Reducing obesity and related chronic disease risk in children and youth: a synthesis of evidence with 'best practice' recommendations. Obesity reviews: an official journal of the International Association for the Study of Obesity. 2006; 7 Suppl 1:7-66. https://doi.org/10.1111/j.1467-789X.2006.00242.x PMID: 16371076.

4. Abdelaal M, le Roux CW, Docherty NG. Morbidity and mortality associated with obesity. Ann TransI Med. 2017; 5(7):161. Epub 2017/05/10. https://doi.org/10.21037/atm.2017.03.107 PMID: 28480197; PubMed Central PMCID: PMC5401682. 
5. Flegal KM, Graubard BI, Williamson DF, Gail MH. Cause-specific excess deaths associated with underweight, overweight, and obesity. JAMA. 2007; 298(17):2028-37. Epub 2007/11/08. https://doi.org/10. 1001/jama.298.17.2028 PMID: 17986696.

6. Ozaltin E, Hill K, Subramanian SV. Association of maternal stature with offspring mortality, underweight, and stunting in low- to middle-income countries. Jama. 2010; 303(15):1507-16. https://doi.org/10.1001/ jama.2010.450 PMID: 20407060; PubMed Central PMCID: PMC3100588.

7. Lange BJ, Gerbing RB, Feusner J, Skolnik J, Sacks N, Smith FO, et al. Mortality in overweight and underweight children with acute myeloid leukemia. Jama. 2005; 293(2):203-11. https://doi.org/10. 1001/jama.293.2.203 PMID: 15644547.

8. Visscher TL, Seidell JC, Menotti A, Blackburn H, Nissinen A, Feskens EJ, et al. Underweight and overweight in relation to mortality among men aged $40-59$ and 50-69 years: the Seven Countries Study. American journal of epidemiology. 2000; 151(7):660-6. https://doi.org/10.1093/oxfordjournals.aje. a010260 PMID: 10752793.

9. Roh L, Braun J, Chiolero A, Bopp M, Rohrmann S, Faeh D, et al. Mortality risk associated with underweight: a census-linked cohort of 31,578 individuals with up to 32 years of follow-up. BMC Public Health 2014; 14:371. Epub 2014/04/18. https://doi.org/10.1186/1471-2458-14-371 PMID: 24739374; PubMed Central PMCID: PMC4021191.

10. Mossey JM, Shapiro E. Self-rated health: a predictor of mortality among the elderly. American journal of public health. 1982; 72(8):800-8. https://doi.org/10.2105/ajph.72.8.800 PMID: 7091475; PubMed Central PMCID: PMC1650365.

11. Idler EL, Benyamini Y. Self-rated health and mortality: a review of twenty-seven community studies. Journal of health and social behavior. 1997; 38(1):21-37. PMID: 9097506.

12. Heidrich J, Liese AD, Lowel $\mathrm{H}$, Keil U. Self-rated health and its relation to all-cause and cardiovascular mortality in southern Germany. Results from the MONICA Augsburg cohort study 1984-1995. Annals of epidemiology. 2002; 12(5):338-45. https://doi.org/10.1016/s1047-2797(01)00300-3 PMID: 12062922.

13. Osoba $\mathrm{D}$. What has been learned from measuring health-related quality of life in clinical oncology. European journal of cancer. 1999; 35(11):1565-70. https://doi.org/10.1016/s0959-8049(99)00192-6 PMID: 10673963.

14. Gill TM, Feinstein AR. A critical appraisal of the quality of quality-of-life measurements. Jama. 1994; 272(8):619-26. PMID: 7726894.

15. Coates A, Porzsolt F, Osoba D. Quality of life in oncology practice: prognostic value of EORTC QLQC30 scores in patients with advanced malignancy. European journal of cancer. 1997; 33(7):1025-30. https://doi.org/10.1016/s0959-8049(97)00049-x PMID: 9376182.

16. Eurenius $E$, Lindkvist $M$, Sundqvist $M$, Ivarsson A, Mogren I. Maternal and paternal self-rated health and BMI in relation to lifestyle in early pregnancy: the Salut Programme in Sweden. Scand J Public Health. 2011; 39(7):730-41. Epub 2011/09/21. https://doi.org/10.1177/1403494811418279 PMID: 21930619.

17. Herman KM, Hopman WM, Rosenberg MW. Self-rated health and life satisfaction among Canadian adults: associations of perceived weight status versus BMI. Quality of life research: an international journal of quality of life aspects of treatment, care and rehabilitation. 2013; 22(10):2693-705. https://doi. org/10.1007/s11136-013-0394-9 PMID: 23539466.

18. Imai K, Gregg EW, Chen YJ, Zhang P, de Rekeneire N, Williamson DF. The association of BMI with functional status and self-rated health in US adults. Obesity. 2008; 16(2):402-8. https://doi.org/10. 1038/oby.2007.70 PMID: 18239651.

19. Okosun IS, Choi S, Matamoros T, Dever GE. Obesity is associated with reduced self-rated general health status: evidence from a representative sample of white, black, and Hispanic Americans. Prev Med. 2001; 32(5):429-36. Epub 2001/05/02. https://doi.org/10.1006/pmed.2001.0840 PMID: 11330993.

20. Prosper MH, Moczulski VL, Qureshi A. Obesity as a predictor of self-rated health. Am J Health Behav. 2009; 33(3):319-29. Epub 2008/12/10. https://doi.org/10.5993/ajhb.33.3.10 PMID: 19063653.

21. Heo M, Allison DB, Faith MS, Zhu S, Fontaine KR. Obesity and quality of life: mediating effects of pain and comorbidities. Obes Res. 2003; 11(2):209-16. https://doi.org/10.1038/oby.2003.33 PMID: 12582216.

22. Wang A, Arah OA. Body Mass Index and Poor Self-Rated Health in 49 Low-Income and Middle-Income Countries, By Sex, 2002-2004. Prev Chronic Dis. 2015; 12:E133. Epub 2015/08/21. https://doi.org/10. 5888/pcd12.150070 PMID: 26292064; PubMed Central PMCID: PMC4556100.

23. Fürnsinn C, Noh J-W, Kim J, Yang Y, Park J, Cheon J, et al. Body mass index and self-rated health in East Asian countries: Comparison among South Korea, China, Japan, and Taiwan. Plos One. 2017; 12 (8). https://doi.org/10.1371/journal.pone.0183881 PMID: 28846742 
24. Kang YW, Ko YS, Kim YJ, Sung KM, Kim HJ, Choi HY, et al. Korea Community Health Survey Data Profiles. Osong Public Health Res Perspect. 2015; 6(3):211-7. Epub 2015/10/03. https://doi.org/10.1016/j. phrp.2015.05.003 PMID: 26430619; PubMed Central PMCID: PMC4551141.

25. Jeong J-y Kim D-H, Kim K-Y Ryu SY, Lee S-Y Park YS. Accuracy of Self-reported Height, Weight and Body Mass Index in Community Health Survey in South Korea. Journal of Health Informatics and Statistics. 2017; 42(3):241-9. https://doi.org/10.21032/jhis.2017.42.3.241

26. Appropriate body-mass index for Asian populations and its implications for policy and intervention strategies. The Lancet. 2004; 363(9403):157-63. https://doi.org/10.1016/s0140-6736(03)15268-3

27. Jylhä $M$. What is self-rated health and why does it predict mortality? Towards a unified conceptual model. Social Science \& Medicine. 2009; 69(3):307-16. https://doi.org/10.1016/j.socscimed.2009.05. 013 PMID: 19520474

28. Tamhane AR, Westfall AO, Burkholder GA, Cutter GR. Prevalence odds ratio versus prevalence ratio: choice comes with consequences. Statistics in Medicine. 2016; 35(30):5730-5. https://doi.org/10.1002/ sim.7059 PMID: 27460748

29. Regression Modeling Strategies2001.

30. Lauretani F, Russo CR, Bandinelli S, Bartali B, Cavazzini C, Di lorio A, et al. Age-associated changes in skeletal muscles and their effect on mobility: an operational diagnosis of sarcopenia. Journal of Applied Physiology. 2003; 95(5):1851-60. https://doi.org/10.1152/japplphysiol.00246.2003 PMID: 14555665

31. Bhaskaran K, dos-Santos-Silva I, Leon DA, Douglas IJ, Smeeth L. Association of BMI with overall and cause-specific mortality: a population-based cohort study of 3.6 million adults in the UK. The Lancet Diabetes \& Endocrinology. 2018; 6(12):944-53. https://doi.org/10.1016/s2213-8587(18)30288-2

32. O'Rourke RW. Obesity and Cancer. Metabolic Syndrome and Diabetes2016. p. 111-23.

33. Piche ME, Poirier P, Lemieux I, Despres JP. Overview of Epidemiology and Contribution of Obesity and Body Fat Distribution to Cardiovascular Disease: An Update. Prog Cardiovasc Dis. 2018; 61(2):103-13. Epub 2018/07/03. https://doi.org/10.1016/j.pcad.2018.06.004 PMID: 29964067.

34. Calle EE, Rodriguez C, Walker-Thurmond K, Thun MJ. Overweight, obesity, and mortality from cancer in a prospectively studied cohort of U.S. adults. N Engl J Med. 2003; 348(17):1625-38. Epub 2003/04/ 25. https://doi.org/10.1056/NEJMoa021423 PMID: 12711737.

35. Ko H-Y, Lee J-K, Shin J-Y, Jo E. Health-Related Quality of Life and Cardiovascular Disease Risk in Korean Adults. Korean Journal of Family Medicine. 2015; 36(6). https://doi.org/10.4082/kjfm.2015.36.6. 349 PMID: 26634104

36. Gallagher D, Visser M, Sepulveda D, Pierson RN, Harris T, Heymsfield SB. How useful is body mass index for comparison of body fatness across age, sex, and ethnic groups? Am J Epidemiol. 1996; 143 (3):228-39. Epub 1996/02/01. https://doi.org/10.1093/oxfordjournals.aje.a008733 PMID: 8561156.

37. Camhi SM, Bray GA, Bouchard C, Greenway FL, Johnson WD, Newton RL, et al. The relationship of waist circumference and BMI to visceral, subcutaneous, and total body fat: sex and race differences. Obesity (Silver Spring). 2011; 19(2):402-8. Epub 2010/10/16. https://doi.org/10.1038/oby.2010.248 PMID: 20948514; PubMed Central PMCID: PMC3960785.

38. Hulman A, Ibsen DB, Laursen ASD, Dahm CC. Body mass index trajectories preceding first report of poor self-rated health: A longitudinal case-control analysis of the English Longitudinal Study of Ageing. Plos One. 2019; 14(2). https://doi.org/10.1371/journal.pone.0212862 PMID: 30794702

39. UI-Haq Z, Mackay DF, Fenwick E, Pell JP. Impact of metabolic comorbidity on the association between body mass index and health-related quality of life: a Scotland-wide cross-sectional study of 5,608 participants. BMC Public Health. 2012; 12(1). https://doi.org/10.1186/1471-2458-12-143 PMID: 22364437

40. Aune D, Sen A, Prasad M, Norat T, Janszky I, Tonstad S, et al. BMI and all cause mortality: systematic review and non-linear dose-response meta-analysis of 230 cohort studies with 3.74 million deaths among 30.3 million participants. Bmj. 2016. https://doi.org/10.1136/bmj.i2156 PMID: 27146380

41. Berrington de Gonzalez A, Hartge P, Cerhan JR, Flint AJ, Hannan L, Maclnnis RJ, et al. Body-Mass Index and Mortality among 1.46 Million White Adults. New England Journal of Medicine. 2010; 363 (23):2211-9. https://doi.org/10.1056/NEJMoa1000367 PMID: 21121834 